\title{
UM RELATO DE EXPERIÊNCIA DE TRADUÇÃO
}

\author{
Maria Elizabeth Chaves de Mello
}

\begin{abstract}
RESUMO:
O presente trabalho relata uma experiência de tradução de um texto teatral - 1789 - A Revolução, de Ariane Mnouchkine - encenado em 1989, no Rio de Janeiro, para comemorar o bicentenário da Revolução Francesa. O texto apresenta as dificuldades suscitadas por esse trabalho e as reflexóes teóricas delas decorrentes.

PALAVRAS-CHAVE: tradução; teatro; encenação
\end{abstract}

\begin{abstract}
ntes de começar o relato de uma experiência, com a consequente reflexão sobre o ato tradutório, seria interessante retomarmos Lalgumas questóes de Antoine Compagnon, no seu livro Le démon de la théorie:
\end{abstract}

Que faz o leitor com o texto, quando lê? E que faz o texto com ele (leitor)?A leitura é ativa ou passiva? Mais ativa que passiva? Ou mais passiva do que ativa? Desenvolve-se como uma conversa, em que os interlocutores teriam a possibilidade de corrigir o equívoco? O modelo habitual da dialética seria suficiente? O leitor deveria ser concebido como um conjunto de reaçôes individuais, ou como a atualização de uma competência coletiva? A imagem de um leitor em liberdade vigiada, controlado pelo texto, seria a melhor? (COMPAGNON, 1998, p. 156)

É impossível pensar no trabalho do tradutor sem ter em conta todas essas indagaçóes, sem tentar responder a elas. No intuito de uma reflexão que se quer a mais aberta possível a todo tipo de teorias, gostaria de retomar algumas 
delas, baseada numa experiência de tradução de teatro. É pensando nessas questóes teóricas que retomamos esse trabalho de tradução, realizado há muitos anos, em 1989, tendo sempre presente uma citação de Millôr Fernandes, a respeito do seu trabalho com o texto Hamlet, de Shakespeare: "É evidente que traduzir o Hamlet é mais difícil do que escrever o Hamlet. Fique claro que não quero dizer mais importante. Mas reescrever a peça - a mesma peça numa outra língua, 384 anos depois - é como escrever amarrado, segurando a caneta com a boca ou batendo na máquina com a ponta do nariz" (FERNANDES, 1989, p. 76).

Esa imagem do escrever amarrado, embora possa parecer exagerada e pretensiosa, exprime, guardadas as proporções (já que, no caso presente, não há distância grande no tempo entre o texto original e a traduçáo), as dificuldades que vivi, ao traduzir 1789 - A Revolução, de Ariane Mnouchkine. Foi muito temerosa que aceitei, no início de 1989, o convite de Carlos Wilson Silveira para traduzir a peça, que seria encenada na Fundição Progresso naquele ano, para comemorar o bicentenário da Revoluçáo Francesa. A tarefa era árdua: tratava-se de preparar a tradução num prazo bem curto, pois era preciso tomar uma série de medidas que dependiam do texto estar pronto, com aprovaçáo do projeto no Théâtre de la Cartoucherie, para poder dar entrada na SBAT.

A peça em francês se apresentava como um livro de imagens sobre a Revolução Francesa: não um livro de História, mas um conjunto de sketches escolhidos pelos membros da trupe para mostrar a Revolução através dos olhos dos que a teriam vivido, lutando para destruir as imagens herdadas da tradição burguesa. Ou seja, um texto questionador, que trazia a proposta de uma reflexão sobre aqueles acontecimentos históricos, apresentando-os de maneira bem diferente daquilo que o público conhecia nos livros escolares. Tratava-se, na verdade, de desmitificar a Revoluçấo Francesa, mostrando os seus bastidores, ou seja, a luta da burguesia pela tomada do poder através da manipulação do povo. E tudo isso deveria ser levado em conta para poder ser dito em outra língua, mostrado a um público que há séculos vinha sendo preparado para uma visão inteiramente mitificadora da Revolução.

Junto com Alcida Brant, iniciamos a tarefa de passar para o português o texto de Ariane Mnouchkine. Nossa primeira preocupação foi de fazer logo um grande copião, uma primeira versão completa, realizada às pressas, para que, a partir dela, pudéssemos realmente trabalhar. Surgiu logo um proble- 
ma: não havia cotejo possível de outras traduções da peça, a não ser a que fora feita para um filme que existia em vídeo na Aliança Francesa. Vimos, então, essa versão, comparando a nossa tradução com as legendas. Mas não havia nenhum enriquecimento possível para o nosso texto, dadas as diferenças fundamentais entre o trabalho de tradução para o cinema (associado ao de legendagem) e para o teatro.

Constatamos logo uma questão: para o tradutor de texto teatral, é fundamental um grande domínio dos registros de língua. No nosso caso, tínhamos a fala do rei e da rainha, dos nobres, dos burgueses, do clero, do povo. Tratava-se de saber lidar com as formas orais do português, que dessem conta de todas essas categorias. Além disso, a peça oscilava entre vários gêneros: épico, dramático, cômico etc., o que exigia uma grande desenvoltura da nossa parte.

Optamos, então, por manter o registro neutro para as falas do rei, da rainha, nobres e burgueses, como havia decidido Ariane Mnouchkine, cujo texto só apresenta diferença marcante quando é o povo que se exprime. Para este último, adotamos a linguagem mais familiar possível, como víamos no texto original. Mas aí entra a primeira e uma das mais ricas contribuiçôes dos atores: quando os ensaios começaram, eles sentiram que ainda não havia suficiente distinção entre a fala popular e a das classes dominantes; e iniciaram várias tentativas de modificaçóes, que redundaram inclusive em mudanças de sotaques. Havia um ator natural de Presidente Prudente (Estado de São Paulo), que imitava perfeitamente o sotaque caipira dessa região: acabamos decidindo que o povo poderia falar assim, estabelecendo-se uma fronteira maior entre a fala popular e as de todas as demais categorias. Deste modo, foi sendo organizado, à medida que o texto era ensaiado, um trabalho de reflexão coletiva, que muito enriqueceu a nossa peça.

Outro exemplo foi em relação à palavra gabelle. Fomos procurar nos livros de História e vimos que gabela é usada em português e a colocamos no texto. Mas, na hora dos ensaios, os atores levantaram a questão de que ninguém iria saber do que se tratava. E era uma palavra importante no texto! O que fazer, já que teatro não tem pé de página? A solução encontrada pelo diretor Carlos Wilson foi a seguinte: a primeira vez em que a palavra era dita, um dos atores, misturado ao público, perguntava, como se fosse um espectador comum

- O que é gabela?

E outro ator, do palco, respondia-lhe: 
- Originalmente, era o imposto sobre o sal. Depois a palavra se estendeu a todo imposto indireto, às taxas que naquela época tanto faziam sofrer o povo.

Assim, resolvia-se o problema da explicação da palavra, substituindo-se o pé-de-página por um recurso cênico.

Um outro exemplo de dificuldades encontradas foi em relação à canção que se segue à Convocação dos Estados Gerais. Era preciso manter o sentido do texto e, ao mesmo tempo, tentar conservar as rimas, a métrica etc.

Em francês :

Or, écoutez petis et grands

l'histoire d'un roi de vingt ans

qui va nous ramener en France

les bonnes moeurs et l'abondance.

D'après ce plan que deviendront

et les catins et les fripons?

s'il veut de l'honneur et des moeurs

que deviendront les grands seigneurs ?...

Em português :

Ouçam, grandes e pequenos

a história de um rei de vinte anos

que vai trazer de volta à França

os bons costumes e a abundância.

Se isso acontecer, em que se tornarão

as putas e os cafetãos?

Se ele quer honra e grandeza

o que será da nobreza?

Tentamos de tudo, mas o resultado, mesmo assim, ficou muito aquém das nossas ambiçóes. Faltava ritmo e musicalidade ao nosso texto. Carlos Wilson queria que essa cena fosse cantada por meia dúzia de atrizes, com toda uma mise-en-scène que demonstrasse a importância daquele momento na peça. Foi um trabalho de recriação coletiva, mas cujo resultado nos deixou insatis- 
feitas, levando-nos a indagar das possibilidades da tradução literária para o teatro: até que ponto ela seria realmente realizável? E até que ponto o tradutor se torna também poeta, romancista, dramaturgo, para poder dar conta do seu trabalho?

Segundo Nelson Ascher, Poesia não é o mais intraduzivel de uma lingua, mas o que nela há de mais traduzivel (ASCHER, 1989,, p. 148. Itálico do autor.). Ou seja, o texto literário, pelo próprio fato da sua indeterminação, presta-se a um número infinito de interpretaçōes possíveis. Segundo Wolfgang Iser, "o leitor nunca retirará do texto a certeza de que a sua compreensão é a justa” (ISER, 1979, p. 87). O que, evidentemente, torna também infinito o número de possibilidades de traduçôes. E a sensação de que ele nunca está pronto, de que sempre há mais possibilidades de reescrevê-lo, causa no intérprete a frustraçấo, o sentimento de trabalho inacabado.

Com a peça 1789 - A Revolução, fomos descobrindo que a função expressiva da linguagem, predominante no texto literário, é ainda maior no teatro. Por conseguinte, o jogo de conotaçóes aí se torna muito mais importante. A sucessão de palavras, o ritmo, as sonoridades normalmente contêm uma carga de evocaçóes que o tradutor deve levar em conta, porque são pertinentes à mensagem. $\mathrm{Na}$ verdade, espera-se que ele seja capaz de restaurar, na língua de chegada, todo o humor, os jogos de palavras, os trocadilhos, as rimas, as aliteraçóes, enfim, toda a dramaticidade da obra original. Com uma dificuldade suplementar: como teatro não tem pé de página, o tradutor se obriga a fazer grandes malabarismos para que o obscuro e a indeterminação do texto literário possam ser conservados ao serem trazidos à presença do espectador.

Deste modo, o trabalho de tradução teatral necessariamente valoriza a forma, a ponto da linguagem se tornar um fim em si mesma. E quanto mais rica for a obra - e a nossa era riquíssima - mais os planos se sobrepóem, mais ela se presta a múltiplas interpretaçôes, maior é a responsabilidade do tradutor. Isso pode ser verificado ainda em outro momento, o ponto culminante da peça, em que os cinquenta atores, espalhados pelo teatro, contavam ao público reunido à sua volta como é que eles haviam tomado a Bastilha. Essa cena, que Carlos Wilson considerava a mais difícil que ele jamais vira em teatro, continha um texto muito forte, crescendo de intensidade do meio para o fim. Exigia um trabalho de grande concentração dos atores, pois todos falavam ao mesmo tempo para grupos de espectadores que estivessem ao seu alcance; e 
era importante que todos terminassem juntos a frase final. Havia uma carga emocional muito grande no texto e a linguagem deveria se prestar a isso.

Muitos problemas surgiram, como, por exemplo, o fato de alguns atores nunca terem estudado francês, o que tornava penosa para eles a pronúncia dos nomes próprios que teriam que dizer. Como a cena já era bastante difícil, resolvemos eliminar este problema traduzindo todos os que apareciam: Versalhes, Bastilha, Campo de Marte e inúmeros outros. Mas alguns mudavam de sentido, como Invalides, Hotel de Ville etc., que decidimos manter no original, por mais difícil que fosse o ensino da fonética francesa aos atores.

Surgiu também uma outra questão: o texto era em registro popular e, no momento mais intenso da narrativa, o pronome on aparecia em quase todas as frases. Tentamos traduzi-lo por a gente, mas ficava mais pesado em português do que nós, pois este último não precisaria ser repetido o tempo todo, já que a nossa língua tem uma variação verbal muito mais rica do que a francesa.

Por outro lado, inicialmente havíamos traduzido a última frase - on l'a prise, la Bastille, on l'a prise - por nós tomamos a Bastilha, nós tomamos ela! - em bom registro familiar do português do Brasil. Mas, durante os ensaios, vimos que esta frase ficaria totalmente sem força dramática. E mudamos para nós a tomamos! Esses e muitos outros problemas, que não nos caberia agora elucidar, mostrou-nos que o tradutor de teatro vive, mais ainda do que o tradutor de texto literário, a alternância entre criação/recepção. Ele não pode escrever pensando só no texto, pois sabe que terá diretor, atores e espectadores, que receberão o seu texto como leitores, falantes e ouvintes, ou seja, a questão da linguagem terá que ser abordada com muito mais cuidado. Assim, ao mesmo tempo em que o seu trabalho se insere na tradução literária, que se caracteriza, segundo Jean Deslile, pela "sobrecarga estética que se acrescenta ao conteúdo puramente referencial de uma obra” (DESDLILE, 1984, p. 33), ele exige, também, do tradutor, uma competência de teatrólogo, ou seja, que ele seja capaz de reproduzir o aspecto propriamente teatral da obra.

Por outro lado, cumpre não esquecer a definição de Sebastião Uchoa Leite: "Traduzir seria ler o melhor possível" (UCHOA, 1989, p. 140). Em termos de tradução para o teatro, temos uma superposição de leituras: o tradutor, primeiro leitor, que passa para a língua de chegada a sua própria leitura do texto; o diretor, que quer encenar a sua leitura da peça; os atores, que leem inúmeras vezes o texto, antes de interpretá-lo, ou seja, antes de fazerem a sua 
própria leitura; e o público, que, por sua vez, também faz a sua leitura da peça a que está assistindo. No caso do nosso trabalho, ainda havia outra superposição: a própria peça já era uma nova leitura, moderna e questionadora, da Revolução Francesa.

Há mais de três séculos, exatamente na época em que aconteciam os episódios narrados por Ariane Mnouchkine, Diderot escreveu o seu Paradoxo do comediante, no qual defendia a teoria de que o ator não deve se confundir com o seu personagem, mas vê-lo de fora, consciente do artifício da interpretação. $\mathrm{Na}$ verdade, Diderot defendia a tese moderna do distanciamento do intérprete em relação ao seu personagem. $\mathrm{O}$ paradoxo consistiria em ser um outro, permanecendo em si mesmo. Ora, tal como o paradoxo do comediante, o tradutor deve ser um intérprete da obra para o seu leitor. Dele depende a vida da mensagem. Seu trabalho, assim como o do ator, é o de querer ser fiel na diferença, dizendo o mesmo e dizendo fatalmente outra coisa. Sua marca própria é a hesitação entre um termo e outro, porque se hesita sempre entre a repetição e a criação. A tradução, como o trabalho do ator, é sempre uma resposta do momento, um modo de enfrentar a diferença entre as línguas. Sua função é compreender o outro na sua diferença e querer interpretá-lo (UCHOA, 1989, p. 140). Por isso, o nosso trabalho foi táo enriquecedor: assistindo aos ensaios, íamos modificando nosso texto à medida que os atores e o diretor sentiam necessidade. Ou seja, realizando com eles esse trabalho de interpretação em todos os sentidos do termo: na direção, na representação, na tradução.

Retomando, agora, a questão de Antoine Compagnon - O que o leitor faz do texto quando lê? -, que resume o trabalho propriamente dito do tradutor, percebemos que ela supóe, como ponto de partida, que o leitor (e, com mais razão, o tradutor) faça alguma coisa do texto. Essa alguma coisa implica o trabalho do imaginário, a criatividade, as tentativas de resolver as ambiguidades e os vazios do texto, a compreensão da cultura do outro. Enquanto tradutores, estaríamos nós sempre atentos a isso? Quando traduzimos, criamos outro texto, ao mesmo tempo igual e diferente do original e que pode enriquecê-lo e atualizá-lo, se se tratar de um texto antigo, ou datado. Segundo Wolfgang Iser, o que caracteriza o texto literário são os vazios, a indeterminação, que o leitor deve preencher ou resolver. Ora, o tradutor deve, ao mesmo tempo, estar consciente e ser capaz de dar conta disso, e, ao tentar fazê-lo, ele vai certamente criar outros vazios e outras indeterminaçóes, pois o seu texto precisa 
ser, tanto quanto possível, literário. Assim, ele tem sempre presente, empiricamente ou não, que o texto literário é o lugar da ambiguidade e do "não dito" e que, por isso, ele nunca fará nada de preciso, nada de definitivo, que não possa ser interpretado ou melhorado. Toda traduçâo poderia ser melhor, e, portanto, nenhuma tradução é definitiva. $\mathrm{O}$ trabalho do tradutor seria, então, o trabalho da modéstia, da constante conscientização da fragilidade da sua tarefa, enfim, o espaço da reflexão crítica. E, quando se trata de tradução para o teatro, como vimos, essa questáo é muito mais evidente, porque se apresenta todo o tempo, na medida em que o texto é lançado no palco, falado, repetido, ensaiado. E, se o tradutor tiver a oportunidade de participar dos ensaios, como era o nosso caso, o seu trabalho torna-se um laboratório de reflexão teórica, a prática se confundindo com a teoria, todo o tempo.

Como essa problemática é praticamente inesgotável, passemos à segunda questão de Compagnon - E o que faz o texto com ele (leitor)? -, que nos lança no debate sobre o diálogo de culturas, implícito no ato de traduzir. Na verdade, o texto nos traz sempre as leituras de seu autor, não apenas as dos autores que ele leu, mas também a história e a cultura de seu país, de seu povo, da sociedade onde vivia quando o texto foi escrito e que ele tenta recriar através da literatura. Todo esse repertório é apresentado ao leitor-tradutor, que a ele deve responder, colocando e se colocando, a si mesmo, em movimento.

Para o teórico da literatura, a tradução oferece, pelo menos, duas possibilidades de reflexão teórica: por um lado, ela supóe uma representação prévia da cultura de partida, do texto original; por outro lado, o tradutor garante, através do seu trabalho, a sobrevida da obra; as traduçóes multiplicam as faces da obra original e dão aos leitores novas possibilidades de leituras, de interpretação. Assim, diante da terceira questão de Compagnon - A leitura é ativa ou passiva? -, podemos responder afirmativamente, pois a leitura é sempre ativa no ato de traduzir, é através dela que o tradutor póe em movimento a obra original, entrando em contato com o pensamento do outro, para refletir sobre ele e tentar re-criar o texto.

No caso do texto de Ariane Mnouchkine, isso é mais interessante se passarmos à próxima questão de Compagnon - a leitura desenvolve-se como uma conversa, em que os interlocutores teriam a possibilidade de corrigir o equivoco? Podemos observar, no caso da tradução teatral, que não só a tradução é uma conversa entre o tradutor-leitor e o texto, mas que os atores e o diretor 
também interagem, trazendo as suas contribuiçóes, fazendo sugestôes, modificando o texto durante os ensaios.

Finalmente, retomando a última questáo de Compagnon - $A$ imagem de um leitor em liberdade vigiada, controlado pelo texto, seria a melhor? - poderíamos refletir sobre o que seria essa liberdade vigiada durante o trabalho de tradução teatral. Na realidade, o texto guia o leitor, que deve ser, tanto quanto possível, fiel. A questão da fidelidade permanece um dos problemas maiores na teoria da tradução, só causando frustração ao tradutor. Até aonde iria a sua liberdade? Poderia ele ter a liberdade de criar, de melhorar o texto? Seria possível fazê-lo, conservando o mesmo texto? Todas essas questóes devem ser consideradas, cada vez que um tradutor começa um novo trabalho. Guiado pelo texto original, ele deve criar, tanto quanto possível, para que o seu texto seja também literário e, no caso da traduçáo para o teatro, ele deve procurar dar conta, também, do seu caráter propriamente teatral.

Assim, relendo hoje o meu trabalho de anos atrás, insatisfeita com o resultado, percebendo como poderia ainda melhorar o texto hoje, constato que o tradutor realiza, com o escritor traduzido, a descida aos infernos da criação artística, com tudo o que pode haver nela de silêncio, de sofrimento, de "não ditos", de riqueza e de ausência de palavras, de indeterminação, de ambiguidade. E, durante o seu trabalho, ele participa um pouco do mistério da arte de escrever...

\section{Referências}

ASCHER, Nelson: O texto e sua sombra. Revista 34 Letras. n 3. Rio de Janeiro: 34 Letras, 1989.

BÉNARD, Jean-Paul \& HORGUELIN, Paul A. Pratique de la traduction. Québec: Linguatech, 1979.

BENJAMIN, Walter. A Tarefa do Tradutor. Cadernos de Mestrado. Rio de Janeiro: UERJ, 1992.

COMPAGNON, Antoine. Le démon de la théorie. Paris: Seuil, 1998.

DIDEROT, Denis. Entretiens sur le fils naturel - Paradoxe sur le Comédien. Paris: Flammarion, 1981.

FERNANDES, Millôr. Hamlet - a tradução. Revista 34 Letras, n 3. Rio de Janeiro: 34 Letras, 1989. 
ISER, Wolfgang: A interação do texto com o leitor. A literatura e o leitor. LIMA, Luiz Costa( org). Rio de Janeiro: Paz e Terra, 1979.

. L'acte de lecture. Bruxelles: Mardaga, 1976.

MNOUCHKÏNE, Ariane. 1789 - La Révolution (trad. BRANT, Alcida \& CHAVES DE MELLO, Maria Elizabeth). Rio de Janeiro: SBAT, 1989.

UCHOA LEITE, Sebastiâo. Texto do Colóquio sobre Interpretação - UERJ, 1988. Revista 34 Letras. n 3. Rio de Janeiro: 34 Letras, 1989.

\section{RAPPORT D'EXPÉRIENCE DE TRADUCTION}

\section{RÉSUMÉ:}

Ce travail rend compte d'une expérience de traduction d'un texte théâtral - 1789 - La Révolution, d'Ariane Mnouchkine - mis en scène en 1989, à Rio de Janeiro, pour fêter le bicentenaire de la Révolution Française. Le texte présente les difficultés suscitées par la traduction, et les réflexions théoriques qui en découlent.

MOTS-CLÉS: traduction; théâtre; mise-en-scène

Recebido em: 12/08/2013 Aprovado em: 15/10/2013 